\title{
The Role of Helminths in Immunity
}

Deepak $\mathrm{T}^{1}$ and Goyal $\mathrm{K}^{2^{*}}$

${ }^{1}$ Department of Medical Microbiology, Postgraduate Institute of Medical Education \& Research, Chandigarh, India

${ }^{2}$ Department of Medical Parasitology, Postgraduate Institute of Medical Education \& Research, Chandigarh, India

*Corresponding author: Goyal K, Department of Medical Parasitology, Postgraduate Institute of Medical Education \& Research, Chandigarh - 160 012, India, Tel: +91-8872288864; E-mail: kapilgoyalpgi@gmail.com

Received date: January 13, 2016; Accepted date: February 11, 2016; Published date: February 18, 2016

Copyright: (C) 2016 Deepak T, et al. This is an open-access article distributed under the terms of the Creative Commons Attribution License, which permits unrestricted use, distribution, and reproduction in any medium, provided the original author and source are credited.

\begin{abstract}
Helminths modulate both the adaptive and innate arms of human immune system. Such immune alteration seems to have an anti-inflammatory effect. Chronic helminth infections switch the immune response from Th1 to Th2 by various mechanisms and by different helminth derived molecules. Though these immunological responses provide a survival advantage, they seem to hamper the response to non-helminth derived antigens. Immune response to oral vaccines and many auto-immune disorders are influenced by immunomodulatory effects of helminths. As a part of eukaryotic community in the gut, helminths might have a potential role in the development of immune system.
\end{abstract}

\section{Keywords: Helminths; Immunomodulation}

Helminths and humans have existed in close association with each other since the distant past. Helminths are one of the earliest organisms to find a niche in human tissue and humans have evolved over millions of years in their constant presence [1]. Helminths are well recognized as the modulators of the immune system. Both the adaptive and innate arms of human immune system are influenced by helminths. It has been established from the studies that helminths stimulate Th2 type of immunity creating an anti-inflammatory response [2]. ES-62, a glycoprotein derived from Acanthocheilonema vitae is a well-studied molecule in this regard [3]. It has been shown in rodent models that this molecule creates potent anti-inflammatory effects by increasing IL-10 production and decreasing IFN- $\gamma$ and IL-12 which are pro-inflammatory cytokines [3]. Similarly other studies have found that helminth infection can lead to an increase in IL-4 level [4], increase in IL-5 release [4], increase in IgE level [5], increase in $\mathrm{CD}^{+} / \mathrm{GFP}^{+}$Th2 cells in lymphoid organs [6], and manipulate the maturation of dendritic cells [7]. Various molecules derived from helminths seem to play a key role in immune modulation. These molecules are found to act by various means. Certain helminth derived molecules are homologues of mammalian anti-inflammatory cytokines [8]. Some protease inhibitors secreted by helminths are found to affect the antigen presentation by antigen presenting cells [9] and some of them are found to stimulate the Toll-like receptors as well [10]. Though various mechanisms and different molecules were found to exert these effects, it is evident that chronic helminth infections switch the immune response from Th1 to Th2. Helminths have been found to induce $\mathrm{T}$ regulatory as well as $\mathrm{B}$ regulatory cells [11]. Th17, one of the important pro-inflammatory $\mathrm{T}$ cell subset is found to be inhibited by helminths in experimental animal models [12]. Apart from these effects helminths have been found to hamper the complement pathway and can breakdown the antibodies $[13,14]$.

Though helminth induced immunological responses offer a survival advantage to them, they seem to hamper the response to non-helminth derived antigens. It is evident from epidemiological as well as animal studies that helminth infection influence many auto-immune disorders like inflammatory bowel disease, rheumatoid arthritis, multiple sclerosis and type-1 diabetes [11]. Helminths seem to decrease inflammation in autoimmune diseases substantiating the hygiene hypothesis. These observations resulted in the idea of using helminth derived molecules in the treatment of autoimmune disorders [11]. When there is a co-infection, immune hypo-responsiveness caused by helminths might affect other organisms also. It has been observed in vaccine trials that the response to oral vaccines was different in developed and developing countries [15]. The high burden of helminth infections in developing countries might be a contributing factor in the attenuated response to mucosal vaccines [15]. It may be due to poor absorption of vaccines in the gut and Th2 immune status induced by helminths [10].

The commensal organisms of an individual play an important role in development of immunity. Initial studies on enumerating gut microbiota have concentrated on the prokaryotes. Recent studies have documented that helminths are one of the main components of eukaryotic community in the gut [16]. The helminths have been found to interact and influence other commensal organisms [17]. Therefore helminths can influence the immunity directly by themselves and indirectly by their interaction with other commensal organisms. Thus helminthes, as parasites or commensals, are the modulators of our immune system not only in disease but also in health. More research in future on commensal helminths will expand our current knowledge on their role in development of immune system.

\section{References}

1. Rook GA (2010) 99th Dahlem conference on infection, inflammation and chronic inflammatory disorders: darwinian medicine and the 'hygiene' or 'old friends' hypothesis. Clin Exp Immunol 160: 70-79.

2. Anthony RM, Rutitzky LI, Urban JF Jr., Stadecker MJ, Gause WC (2007) Protective immune mechanisms in helminth infection. Nat Rev Immunol 7: 975-987.

3. Harnett W, Harnett MM, Leung BP, Gracie JA, McInnes IB (2004) The anti-inflammatory potential of the filarial nematode secreted product, ES-62. Curr Top Med Chem 4: 553-559. 
4. Hubner MP, Stocker JT, Mitre E (2009) Inhibition of type 1 diabetes in filaria-infected non-obese diabetic mice is associated with a $\mathrm{T}$ helper type 2 shift and induction of FoxP3+ regulatory T cells. Immunology 127: 512-522.

5. Saunders KA, Raine T, Cooke A, Lawrence CE (2007) Inhibition of autoimmune type 1 diabetes by gastrointestinal helminth infection. Infect Immun 75: 397-407.

6. Mohrs K, Harris DP, Lund FE, Mohrs M (2005) Systemic dissemination and persistence of Th2 and type 2 cells in response to infection with a strictly enteric nematode parasite. J Immunol 175: 5306-5313.

7. Everts B, Smits HH, Hokke CH, Yazdanbakhsh M (2010) Helminths and dendritic cells: sensing and regulating via pattern recognition receptors, Th2 and Treg responses. Eur J Immunol 40: 1525-1537.

8. Danilowicz-Luebert E, O'Regan NL, Steinfelder S, Hartmann S (2011) Modulation of specific and allergy-related immune responses by helminths. J Biomed Biotechnol 2011: 821578.

9. Klotz C, Ziegler T, Danilowicz-Luebert E, Hartmann S (2011) Cystatins of parasitic organisms. Adv Exp Med Biol 712: 208-221.

10. van Riet E, Hartgers FC, Yazdanbakhsh M (2007) Chronic helminth infections induce immunomodulation: consequences and mechanisms. Immunobiology 212: 475-490.

11. Bashi T, Bizzaro G, Ben-Ami Shor D, Blank M, Shoenfeld Y (2015) The mechanisms behind helminth's immunomodulation in autoimmunity. Autoimmun Rev 14: 98-104.
12. Wu Z, Nagano I, Asano K, Takahashi Y (2010) Infection of nonencapsulated species of Trichinella ameliorates experimental autoimmune encephalomyelitis involving suppression of Th17 and Th1 response. Parasitol Res 107: 1173-1188.

13. Auriault C, Ouaissi MA, Torpier G, Eisen H, Capron A (1981) Proteolytic cleavage of IgG bound to the $\mathrm{Fc}$ receptor of Schistosoma mansoni schistosomula. Parasite Immunol 3: 33-44.

14. Ouaissi MA, Auriault C, Santoro F, Capron A (1981) Interaction between Schistosoma mansoni and the complement system: role of IgG FC peptides in the activation of the classical pathway by schistosomula. J Immunol 127: 1556-1559.

15. Cooper PJ, Chico M, Sandoval C, Espinel I, Guevara A, et al. (2001) Human infection with Ascaris lumbricoides is associated with suppression of the interleukin-2 response to recombinant cholera toxin $b$ subunit following vaccination with the live oral cholera vaccine CVD 103-HgR. Infect Immun 69: 1574-80.

16. Parfrey LW, Walters WA, Lauber CL, Clemente JC, Berg-Lyons D, et al. (2014) Communities of microbial eukaryotes in the mammalian gut within the context of environmental eukaryotic diversity. Front Microbiol 5: 298.

17. Berrilli F, Di Cave D, Cavallero S, D'Amelio S (2012) Interactions between parasites and microbial communities in the human gut. Front Cell Infect Microbiol 2: 141. 